ARCHIVO ESPAÑOL DE ARTE, LXXXIV, 334

ABRIL-JUNIO 2011, pp. 163-170

ISSN: 0004-0428

\title{
VARIA
}

\section{COMPAÑÍA ARTÍSTICA ENTRE JUAN DE OVIEDO Y DE LA BANDERA Y JUAN MARTÍNEZ MONTAÑÉS. UNA APORTACIÓN INÉDITA A SUS RESPECTIVAS BIOGRAFÍAS}

\begin{abstract}
En este artículo se da a conocer una compañía artística hasta el momento inédita entre los escultores sevillanos Juan de Oviedo y de la Bandera y Juan Martínez Montañés. Fue firmada en 1596 y tenía una duración de seis años, durante los cuales labrarían conjuntamente los retablos mayores de las parroquias de Cazalla de la Sierra, Villamartín y Aracena, además de repartirse las ganancias que generaran los encargos escultóricos recibidos durante este periodo.
\end{abstract}

Palabras clave: Escultura; Retablo; Finales del siglo XVI; Sevilla; Juan de Oviedo y de la Bandera; Juan Martínez Montañés.

\section{THE ARTISTIC COMPANY BETWEEN JUAN DE OVIEDO Y DE LA BANDERA \& JUAN MARTÍNEZ MONTAÑÉS: AN UNPUBLISHED CONTRIBUTION TO THEIR RESPECTIVE BIOGRAPHIES}

This article presents a heretofore-unknown artistic company formed between the Sevillian sculptors Juan de Oviedo y de la Bandera and Juan Martínez Montañés, established in 1596 and which lasted six years. During this period they worked together on the altarpieces of the parish churches of Cazalla de la Sierra, Villamartín and Aracena, and shared the earnings from their sculptural projects.

Key words: Sculpture; Altarpiece; Late $16^{\text {th }}$ Century; Seville; Juan de Oviedo y de la Bandera; Juan Martínez Montañés.

Juan de Oviedo y de la Bandera y Juan Martínez Montañés siempre han sido considerados figuras claves en el desarrollo y evolución del arte hispalense durante las últimas décadas del siglo XVI y la primera mitad del XVII. Ya su contemporáneo Pacheco nos alertaba de la genialidad de estos artistas, aunque no será hasta principios de la centuria pasada cuando comiencen a elaborarse sólidas monografías que permitieron conocer de una manera mucho más profunda y clara la trascendencia creativa de estos grandes maestros ${ }^{1}$. La labor emprendida por José Gesto-

\footnotetext{
${ }^{1}$ Pacheco ya alabó las excelencias de Oviedo en su libro de verdaderos retratos publicado en 1599, mientras que a Martínez Montañés lo menciona posteriormente en su Arte de la Pintura aludiendo a su amistad, admiración y fama, PACHeCo, F.: Libro de descripción de verdaderos Retratos de Ilustres y Memorables Varones, Sevilla, 1985, pp. 145149; El Arte de la Pintura, Madrid, 2001 (2. ${ }^{\text {a }}$ edición), p. 372; con posterioridad serán Palomino y Ceán Bermúdez los
} 
so y Pérez, Celestino López Martínez, María Elena Gómez Moreno y especialmente José Hernández Díaz, entre otros muchos que continuaron sus pasos, fue esencial para exhumar del olvido una ingente documentación que posibilitó un acercamiento real a ambas personalidades y a una sobresaliente producción artística que puso a los mismos y a la escuela sevillana en la vanguardia artística de esta época ${ }^{2}$.

Pero nuestro cometido no es exponer aquí sus principales logros, algo sobradamente conocido, sino ahondar en un periodo concreto de sus vidas en el que tuvieron una estrecha colaboración profesional, la cual hasta ahora se intuía y que, gracias a la localización del documento inédito que presentamos, queda totalmente ratificada. En concreto se trata de la compañía artística que mantienen ambos escultores entre 1596 y 1602, años que se corresponden con el periodo de consolidación artística y de mayor desarrollo de la faceta escultórica y retablística de Oviedo el Mozo y con la etapa de iniciación profesional de Martínez Montañés ${ }^{3}$. Ciertamente era conocida tal vinculación gracias a una declaración realizada por ambos el 9 de agosto de 1597, cuando deciden realizar un retablo para el convento de Santa Clara de Llerena, considerando además la posibilidad de trabajar de forma conjunta en años venideros, pero nada se dice en esta carta de la aludida unión que pactaron un año antes y que pasaremos seguidamente a analizar ${ }^{4}$.

En concreto, será el 5 de junio de 1596 cuando Juan de Oviedo el Mozo y Martínez Montañés convengan esta compañía artística, en la cual se establecen cinco capitulaciones que debían seguirse, contemplarse y cumplirse durante los seis años siguientes ${ }^{5}$. No hay la menor duda que Oviedo conoce perfectamente a su compañero y su maestría con la gubia, y que Montañés, por su parte, desea unirse a su amigo para con ello abrirse terreno en un mercado que pronto sucumbiría ante su genialidad. Y esto es lo que perfectamente se deja sentir en el primero de los aludidos capítulos. En él se expone que la escultura de los retablos concertados por Oviedo para

que resalten las virtudes de Martínez Montañés, olvidando la labor artística de Oviedo. PALomino, A.: El Parnaso español pintoresco laureado. Tomo tercero de El Museo Pictórico y Escala Óptica, Madrid, 1947, pp. 861-862; CEÁN BermúdeZ, A.: Diccionario histórico de los más ilustres profesores de las Bellas Artes en España, Madrid, 1800, t. I, pp. 84-94.

${ }^{2}$ Gestoso y PÉrez, J.: Sevilla Monumental y Artística, 3 tomos, Sevilla, 1989-1892; Ensayo de un Diccionario de los artífices que florecieron en Sevilla, 3 tomos, Sevilla 1899-1909; LóPEz MARTínEZ, C.: Maestros Mayores del Concejo Hispalense, Sevilla, 1927; Arquitectos, escultores y pintores vecinos de Sevilla, Sevilla, 1928; Retablos y esculturas de traza sevillana, Sevilla, 1928; Desde Jerónimo Hernández hasta Martínez Montañés, Sevilla, 1929; Desde Martínez Montañés hasta Pedro Roldán, Sevilla, 1932; El escultor y arquitecto Juan de Oviedo y de la Bandera, Sevilla, 1948; Hernández Díaz, J.: "El retablo sevillano del siglo XVII", Sevilla y la Semana Santa, Sevilla, 1931; Imaginería hispalense del Bajo Renacimiento, Sevilla, 1951; Juan Martínez Montañés, Madrid, 1959; Martínez Montañés. El Lisipo andaluz (1558-1648). Arte Hispalense, 10, Sevilla, 1976; Juan Martínez Montañés, Sevilla, 1987; Gómez Moreno, M. E.: Juan Martínez Montañés, Madrid, 1942; Montañés entre Juan de Mesa y Alonso Cano. Martínez Montañés (1568-1649) y la escultura andaluza de su tiempo, Madrid, 1971; Proske, B. G.: Juan Martínez Montañés. Sevillian Sculptor, Nueva York, 1967; Pérez Escolano, V.: Juan de Oviedo y de la Bandera. Escultor, Arquitecto e Ingeniero. Arte Hispalense, 16, Sevilla, 1977; PALOMERo, J.: El retablo sevillano del Renacimiento: análisis y evolución (1560-1629), Sevilla, 1983; Passolas, J.: Vida y obra de Martínez Montañés, Sevilla, 2005; MALO, L: "Aportación Documental al Catálogo del Pintor Francisco López Caro: Cuarenta Bodegones para Juan Martínez Montañés”, Laboratorio de Arte, 18 (2005), pp. 311-318; Passolas, J.; LóPEz-Fe, C. M.: Juan Martínez Montañés, Sevilla, 2008.

3 Tanto Víctor Pérez Escolano como José Hernández Díaz establecen estos periodos para sus respectivas biografías. Pérez Escolano, V.: Juan de Oviedo..., ob. cit., pp. 19-29; Hernández Díaz, J.: Juan Martínez Montañés, ob. cit. (1987), pp. 95-110.

${ }^{4}$ Este retablo fue finalmente contratado el 16 de febrero de 1598. Gestoso, José: Ensayo de un diccionario..., ob. cit., t. III, p. 149; López Martínez, C.: Desde Martínez Montañés..., ob. cit., p. 231.

5 Archivo Histórico Provincial de Sevilla. Sección de Protocolos Notariales de Sevilla (a partir de este momento AHPSe. SPNSe.): Legajo 15047, oficio 22, libro 1. ${ }^{\circ}$ de 1596, ff. 1133 r.-1134 r. 
Cazalla de la Sierra, Aracena y Villamartín, Martínez Montañés la tomara como propia en medianería, esto es, que ambos trabajarían al unísono en la escultura de estas tres estructuras lignarias. No obstante, el cometido de Montañés se acerca más al de un oficial, ya que él se encargaría de desbastarla, estucar los desnudos, perfilar los rostros, darles forma y poner las manos a las figuras, mientras que Oviedo, como todo maestro, remataría la creación dándole el retoque final. Situación posiblemente potenciada por la mayor dedicación de este último a la arquitectura de estos retablos. Además, se comprometen a que la madera y el ensamblaje de estas esculturas debían ser costeadas a partes iguales, aunque, como queda dicho en la tercera capitulación, las costas surgidas por los pagos de los retablos debían ser proporcionales a las labores realizadas por ambos, obligándose Juan de Oviedo, en la cuarta disposición, a pagarle a Montañés la parte del dinero correspondiente a su labor escultórica conforme fuera cobrando dichas obras.

Ciertamente esta primera declaración de intenciones es toda una revelación. En primer lugar nos desvela la participación, hasta hoy desconocida, de Martínez Montañés en el desgraciadamente desaparecido retablo mayor de la parroquia de Cazalla de la Sierra; en segundo lugar nos permite conocer el inédito encargo del retablo mayor de la parroquia de la Asunción de Aracena, y del primer intento de creación de un altar mayor para la iglesia de Villamartín; y en tercer lugar se vislumbra la posición privilegiada de Oviedo con respecto al alcalaíno en este momento, como ya hemos tenido ocasión de exponer en su análisis.

Con respecto al retablo de Cazalla, conocido es que se concertó el 9 de febrero de 1592 y que sus obras estaban proyectadas para ser concluidas en tres años, aunque se prolongaron hasta $1607^{6}$. Y realmente en este retraso está una de las causas que llevaron a Oviedo a establecer esta unión artística con Martínez Montañés, a pesar de contar con varios oficiales como Juan de Bruselas y Artús Jordán, quienes en este mismo momento trabajaban en la conclusión del retablo de Azuaga $^{7}$. Pero tal era el volumen de trabajo comprometido, que esta ayuda sin duda se hacía necesaria. Además del casi ya concluido retablo mayor de Constantina, del que no se hace mención en este documento, Oviedo tenía encargados los referidos de Villamartín y Aracena, para los que sí pide a Montañés su colaboración ${ }^{8}$. Sin embargo, el primero quizás no se llegó a iniciar en este momento, ya que el jurado sevillano lo volvería a concertar el 1 de octubre de 1601, constituyéndose Montañés como fiador tanto del arquitecto como de los pintores Vasco de Pereira y Juan y Diego Delgado9 . Retablo que no llegó a construirse hasta bien entrado el siglo XVII por Francisco de Ribas y siguiendo ya un diseño totalmente diferente, de estilo salomónico ${ }^{10}$. Y el que tampoco se comenzó fue el retablo mayor de la iglesia de la Asunción de Aracena, ya que ninguna otra noticia se tiene del mismo hasta su contratación definitiva el 21 de marzo de 1629, con el escultor Juan de Remesal, destacado discípulo de Montañés, y con el pintor Pablo Legot ${ }^{11}$. Una obra que desapareció también en los sucesos de 1936 y que, sin duda, su diseño arquitectó-

${ }^{6}$ López Martínez, C.: Retablos..., ob. cit., pp. 162-164; Arquitectos..., ob. cit., pp. 39, 130; Desde Jerónimo Hernández..., ob. cit., pp. 73, 189; Desde Martínez Montañés..., ob. cit., pp. 114, 116, 121, 178.

7 López Martínez, C.: Desde Jerónimo Hernández..., ob. cit., pp. 63-67; Desde Martínez Montañés..., ob. cit., pp. 116, 146, 149; El escultor y arquitecto..., ob. cit., p. 29. BAGO, M.: Arquitectos, escultores y pintores sevillanos del siglo XVII, D.H.A.A., tomo V, Sevilla, 1932, pp. 88-89.

${ }^{8}$ El retablo mayor de Constantina, destruido también en la Guerra Civil, fue encargado el 15 de junio de 1592 y concluido el 6 de marzo de 1598. AA.VV. Documentos Varios. D.H.A.A., Sevilla, 1928, t. II, pp. 238-239; LóPEZ Martínez, C.: Desde Jerónimo Hernández..., ob. cit., pp. 71-73, 189; Desde Martínez Montañés..., ob. cit, pp. 117, 117, 178.

9 López Martínez, C.: Desde Jerónimo Hernández..., ob. cit., p. 189; Desde Martínez Montañés..., ob. cit., pp. 119-120, 203; El escultor y arquitecto..., ob. cit., pp. 34-35.

${ }_{10}$ Dabrio, M. T.: Los Ribas. Un taller andaluz de escultura del siglo XVII, Córdoba, 1985, pp. 466-472.

${ }^{11}$ López Martínez, C.: Arquitectos, escultores y pintores..., ob. cit., p. 156. 


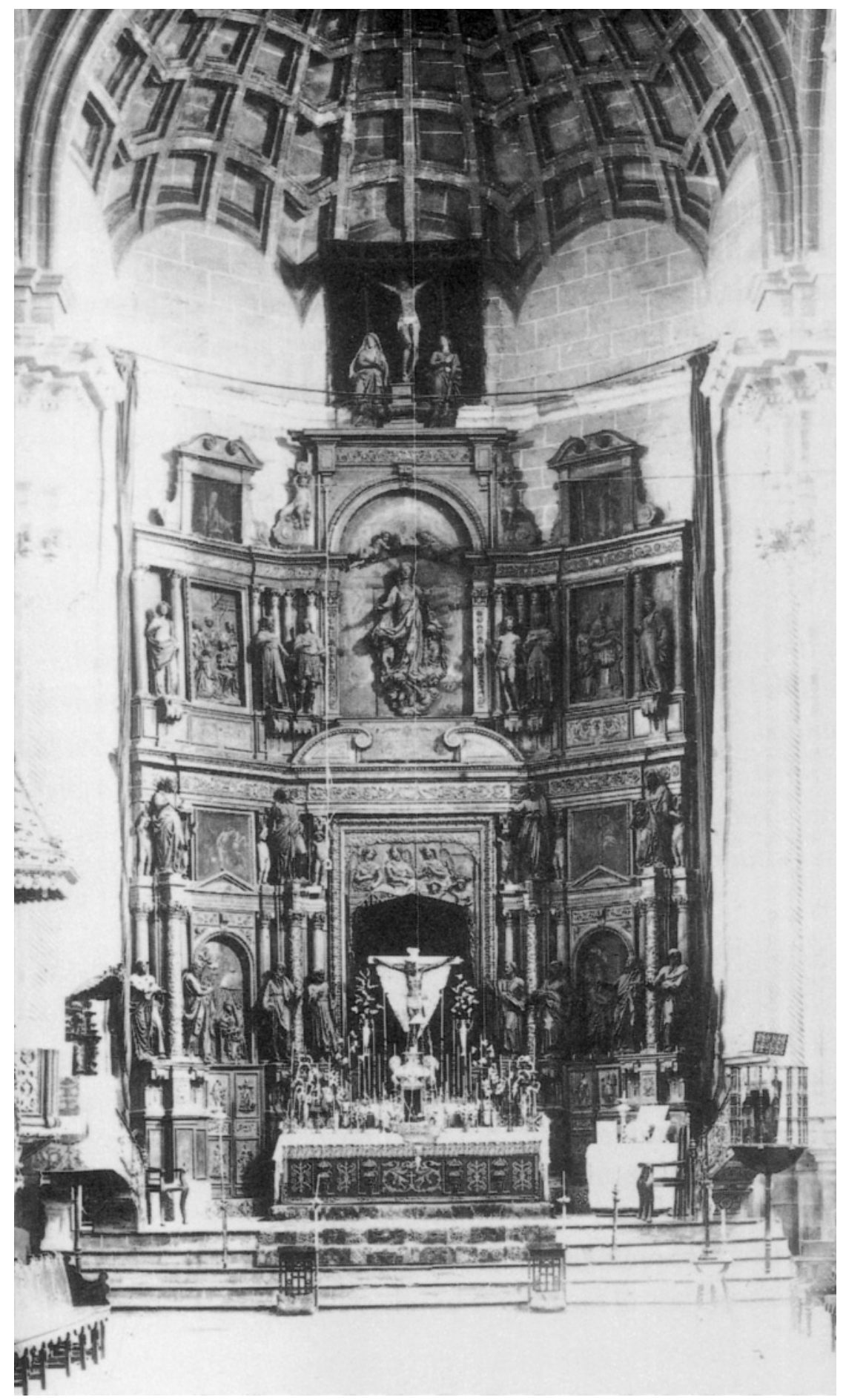

Fig. 1. Retablo mayor de la parroquia de Nuestra Señora de Consolación de Cazalla de la Sierra. Concertado por Juan de Oviedo y de la Bandera en 1592. Desaparecido en la Guerra Civil. Fototeca del Laboratorio de Arte. Universidad de Sevilla. 


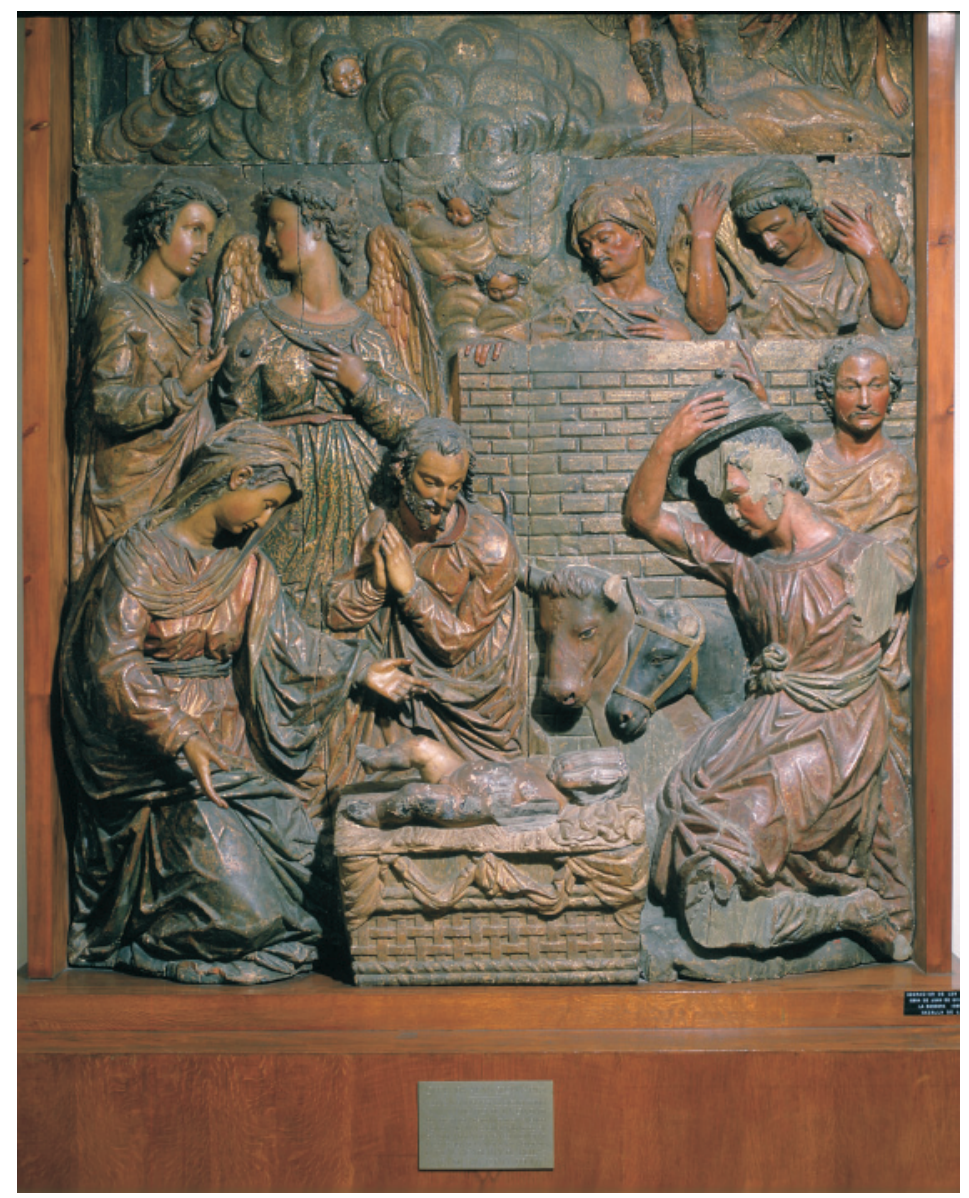

Fig. 2. Relieve de la Adoración de los Pastores del retablo mayor de la parroquia de Nuestra Señora de Consolación de Cazalla de la Sierra. Museu Frederic Marès. Barcelona (Autor de la imagen (C) Museu Frederic Marès. Barcelona).

nico era deudor de las composiciones de Oviedo ${ }^{12}$. Por lo tanto, de esta labor conjunta tan sólo quedan los relieves salvados del desgraciado retablo de Cazalla (fig. 1), en los cuales ya se había intuido la presencia de Montañés. De hecho, el de la Adoración de los Pastores (fig. 2), que hoy se encuentra en el Museo Marés de Barcelona, se había atribuido al maestro alcalaíno antes de su identificación como perteneciente al altar de Cazalla y su consiguiente adjudicación al catálogo de obras de Oviedo y de la Bandera ${ }^{13}$.

Pero como se dijo antes, esta compañía no sólo quedaba prefijada para estos retablos, sino que se hacía extensible a todas aquellas esculturas y ensamblajes que concertasen durante los seis años siguientes. Así se expresaba en el segundo capítulo, aunque en unos puntos muy diferentes a los establecidos para los retablos anteriores. Realmente, lo que se dispone ahora es el reparto

12 PÉrez Embid, F.: "El retablo mayor de Santa María de Aracena y otras obras de arte desaparecidas", Archivo Hispalense, 58 (178), 1975, pp. 69-101.

13 Proske, B. C.: "Relieve de un retablo de Juan de Oviedo", Archivo Español de Arte, 34: 135, 1961 (julio-septiembre), pp. 271-274.

Arch. esp. arte, LXXXIv, 334, ABRIL-JUNIO 2011, 163-170, ISSN: 0004-0428 
a partes iguales de las ganancias y las pérdidas de los encargos vinculados a sus labores como ensambladores, entalladores y escultores. Nueva situación que tampoco es extraña en el ambiente artístico de la época. Otros arquitectos y escultores contemporáneos establecieron parecidos compromisos con la intención de poder sobre todo afrontar fianzas excesivamente elevadas que, en caso de incumplimiento del contrato, podían llevarles a la ruina; o también para poder mejorar la situación económica y la proyección artística de uno de los maestros ${ }^{14}$. Y entre estas dos cuestiones se encuentran parte de las razones que les llevaron a prestarse esta confianza mutua que se perpetuará en una fuerte amistad que mantendrán hasta el fin de sus días.

Por lo tanto, si tenemos en cuenta esta declaración, de las esculturas labradas por Martínez Montañés en estos años, la mitad de lo ganado pudo engrosar las arcas del rico jurado sevillano. Los ejemplos conocidos y documentados en los que ello pudo suceder son la magnífica escultura de San Cristóbal del Salvador, encargada en 1597, y las desaparecidas de la Virgen de la Encarnación y San Miguel que le encomendase Martín de Zúñiga en 1598. Además, también debemos incluir en este conjunto creativo, las esculturas de bulto que labró Montañés para el Túmulo de Felipe II de la Catedral hispalense en 1598, una obra trazada por Juan de Oviedo, quien sin duda debió favorecer la presencia del maestro alcalaíno en tal empresa, para con ello obtener la mitad del dinero que recibiría por lo trabajado. Esto mismo se hacía extensible a las ensambladuras, entrando en esta medianería económica el retablo del monasterio de la Concepción de Panamá, escriturado en 1598 y fiado por el propio Juan de Oviedo, y los del convento de la Concepción de Sevilla y la colegiata de Osuna, ambos de 1602, y en este último trabajando al unísono en el proyecto como tendremos ocasión de comentar ${ }^{15}$.

Y al igual que Montañés, también Oviedo concertó algunas obras en este periodo de las que el primero pudo reembolsarse su parte correspondiente. Las esculturas y retablos conocidos son la desaparecida Virgen del Rosario y su retablo de la parroquial de Constantina de 1598, la imagen de San Francisco del convento franciscano de Cazalla de 1599, el retablo de San Juan Bautista del convento de San Clemente de este mismo año, el retablo e imagen de la Virgen del Buen Aire de la Universidad de los Mareantes de Sevilla de 1600, dos esculturas para América encargadas en este último año, los retablos del convento de Gracia y del cenobio de Pasión de Sevilla, ambos de 1601, y el de la ermita de Ntra. Sra. del Espino del Pedroso, concluido en 1602, además de los referidos antes y concertados conjuntamente, en los que lógicamente se repartían por contrato las ganancias y las pérdidas que tuvieran ${ }^{16}$.

No obstante quedaban fuera del pacto aquellos trabajos cuyo precio fuera menor de diez ducados, los crucificados de marfil y ciprés, y los Niños Jesús de ciprés que no pasaran de una vara de alto, cuyas ganancias se las reservarían para sí cada uno de ellos. Una declaración bastante ilustrativa de la demanda artística del momento, en la que se pusieron de moda las imágenes marfileñas de Crucificados de pequeño formato gracias a las peculiares creaciones de Gaspar Núñez Delgado y que Martínez Montañés también se comprometió a reproducir en 1590 para el presbítero Nicolás Monardes ${ }^{17}$. Pero tampoco faltaron ejemplos anteriores en el quehacer del alcalaíno de estos mismos Cristos labrados en ciprés, como el que concertó el 2 de julio de 1591 con el pintor Alonso

\footnotetext{
14 Palomero PÁramo, J.: El retablo sevillano del Renacimiento..., ob. cit., pp. 30-34.

15 Todas estas obras con sus fuentes documentales se pueden consultar en Hernández DíAz, J.: Juan Martínez Montañés, ob. cit., pp. 100-109.

${ }^{16}$ Igualmente este catálogo de obras de Juan de Oviedo el Mozo lo hemos extraído de Pérez Escolano, V.: Juan de Oviedo y de la Bandera..., ob. cit., pp. 86-88.

17 López Martínez, C.: Nuevos testimonios..., ob. cit., p. 13. Son varios los crucificados de marfil firmados por Gaspar NúÑez Delgado, Lafuente Ferrari, E.: "Esculturas de marfil de Gaspar Núñez Delgado", Revista de Arte Español, 1950, "Un nuevo crucificado de marfil de Gaspar Núñez Delgado", en Boletín de la Real Academia de Bellas Artes de San Fernando, vol. II, núm. 1 (1953), pp. 17-24.
} 
Vázquez, o el que le encargó el presbítero Cristóbal de Rivera el 19 de septiembre de $1592^{18}$. Igualmente la alusión a los Niños Jesús pone de relieve otra de las manifestaciones religiosas de más éxito entre la clientela hispalense, iniciada tras la genial creación de Jerónimo Hernández para la Hermandad de la Quinta Angustia de Sevilla en $1581^{19}$. Sin embargo fue Montañés quien creó el modelo más celebrado de esta iconografía, como fue el famoso Niño Jesús del Sagrario de 1604 y cuyo precedente y ejemplo de su habitual confección la hallamos en el encargo similar que recibió del presbítero Antonio Cordero de Tapia en $1595^{20}$. Por lo tanto, y ante la falta de datos similares de la otra parte, es evidente que este capítulo cuarto fue impuesto por el propio Montañés ya que era él quien tenía una mayor dedicación a estos menesteres de pequeño formato.

La escritura finaliza con una última capitulación en la que se exponen las consabidas fórmulas de todo compromiso, fijándose una multa en caso de incumplimiento valorada en doscientos ducados de oro, una cuantía bastante elevada como para romper esta unión por alguna causa que no fuese mayor ${ }^{21}$. Y parece que ello no sucedió, ya que, como dijimos en un principio, debió resultar bastante fructífera esta compañía para ambas partes, hasta el punto de quererla hacer extensible al campo de la retablística en general, como declararon en la escritura referida de la conveniencia del retablo de Llerena de 1597. Sin embargo, la diferencia ahora es clara, porque se establece el reparto del trabajo a partes iguales de todos los retablos que concertasen juntos, y no las ganancias y pérdidas como habían expresado en el anterior contrato, algo que, ante la buena experiencia de Cazalla, no dudaron ponerla en práctica en varias ocasiones. En concreto, son conocidas su colaboración en el retablo mayor de la iglesia de San Miguel de Jerez de la Frontera que conciertan en 1601 junto a Gaspar del Águila, su unión para labrar el retablo mayor de la colegial de Osuna en 1602 y el del convento de Santa Clara de Cazalla de la Sierra en 1604, y sus actuaciones conjuntas en el del Juicio Final del convento hispalense de Santa Isabel de 1610, o en los magníficos retablos de los Santos Juanes del convento de San Leandro de Sevilla, construidos entre 1620 y $1633^{22}$. No obstante, dicha unión fue bastante flexible, como bien se recoge en la referida declaración de 1597, ya que ello no fue impedimento para que ambos se pudieran comprometer a realizar otras obras de manera individual o en colaboración con otros maestros, siempre y cuando se repartieran a partes iguales sus ganancias y sus perdidas, al menos hasta 1602 , pues no tenemos documentación que nos alerte de lo contrario.

En definitiva, en esta compañía artística y profesional, además de los datos concretos expuestos, se evidencia la situación vital por la que ambos artistas atravesaban en estos años finales del siglo XVI. Por un lado, están claras las intenciones de Juan de Oviedo de proveerse del mejor escultor de la ciudad para sus numerosos encargos que difícilmente podría atender de otra manera. Entendible si tenemos en cuenta que a su reconocimiento artístico le siguió un ascenso en lo social que le llevó a ocupar prestigiosos cargos ciudadanos, como el de Jurado de Sevilla e incluso el de Familiar del Santo Oficio de la Inquisición hispalense, conseguido en 1595. Además, en estos años Oviedo comenzaba a decantarse por otros menesteres artísticos más vinculados con la arquitectura, que le valdrán para convertirse en Maestro Mayor de la Ciudad en 1603. Pero por la parte de Montañés tampoco había desinterés. A pesar de que llevaba años en su ciudad de adopción, aún le faltaba el definitivo espaldarazo para poder hacerse con la más selecta

\footnotetext{
18 López Martínez, C.: Desde Martínez..., ob. cit., p. 229; Desde Jerónimo..., ob. cit., p. 269.

19 Hernández Díaz, J.: Imaginería hispalense en el Bajo Renacimiento, ob. cit., p. 57.

20 López Martínez, C.: Desde Martínez Montañés..., ob. cit., p. 231.

${ }^{21}$ Por ejemplo, por la escultura de San Cristóbal del Salvador de Sevilla se le pagaron a Montañés 110 ducados, por lo que es comprensible lo que suponía esta multa al menos para él en este momento inicial de su carrera. Alonso, A; Palomero, J.; Galdón, M. A.: El San Cristóbal de Martínez Montañés. Una obra maestra documentada en el Archivo Histórico Provincial de Sevilla, Sevilla, 2008, pp. 5-6.

22 Palomero, J.: El retablo sevillano..., ob. cit., pp. 361-362, 275-377, 379-381, 400-404.
} 
clientela sevillana, y que mejor manera que unirse a un maestro que acaparaba los más importantes encargos episcopales, consolidando así una posición que pronto será reconocida por toda la ciudad, convirtiéndose en pocos años en el más afamado y laureado entre sus iguales, además del mejor representante de la escultura sevillana de su tiempo.

\section{APÉNDICE DOCUMENTAL.}

Sevilla, 5 de junio de 1596

Concierto de compañía artística entre Juan de Oviedo y de la Bandera y Juan Martínez Montañés. AHPSe. SPNSe. Legajo 15047, oficio 22, libro 1. ${ }^{\circ}$ de 1596, ff. 1133 r.-1134 r.

"Concierto (al margen). Sepan quantos esta carta vieren como yo Juan de Oviedo escultor vecino de esta ciudad de Sevilla en la collacion de la Madalena de la una parte e yo Joan Martinez Montañes vecino de esta dicha ciudad en la collacion de San Lorenzo de la otra parte otorgamos y conocemos la un parte a la otra que nos convenimos e concertamos con los capitulos y en la forma y manera siguiente:

- Primeramente es capitulo e declaracion que ambos hacemos compañia para en tener en los dichos nuestros artes de escultores y arquitectos por tiempo de seis años que comienzan a correr desde oy dia de la fecha de esta carta en adelante y abemos de hacer por mitad dicha escultura del retablo de Cazalla que se esta haciendo y del retablo de Aracena y del retablo de Villamartin de que estoy encargado yo el dicho Juan de Oviedo e yo el dicho Joan Martinez debo desbastar toda la escultura de todos los dichos tres retablos y rebocar los desnudos de las figuras que en ellos se ofreciere y a de alabar los rostros y poner las manos en estado de lixallas y abrir las uñas de todas las dichas figuras y a de quedar a cargo de mi el dicho Juan de Oviedo el limpiar las dichas figuras y ponerlas y acabarlas de todo punto con la perfeccion que el desbaste requiere para que las dichas figuras sean buenas y en lo que toca a las costas de madera y samblaje de la escultura de los dichos retablos se a de hacer y pagar por mitad entre nos y sin que el uno pague más que el otro y de ello nos abemos de saber a paz e a salvo e por el dicho orden abemos de hacer lo susodicho.

- Iten es declaración que todas las dichas demas obras de ensamblaje y talla y escultura que durante los dichos seis años se nos ofrecieren y acada uno de nos se han de hacer por mitad perdidas o ganancias de la forma y manera que cada uno de nos tomare las dichas obras y abemos de partir las ganancias por mitad y las perdidas si las oliere las abemos de suplir por mitad e las costas y gastos que se hicieren tambien an de ser por mitad y cada uno de nos que cobrare los precios de las dichas obras an de acudir al otro con su mitad enteramente porque asi es concierto.

- Iten es declaracion que en lo que toca a la escultura de los dichos retablos que estan encargados a mi el dicho Joan de Oviedo las costas que en las cobranzas de ellos se hicieren a de ser clara por cantidad conforme a las partes que cada uno de nos tiene en los dichos retablos.

-Yten es declaracion que las obras a que fueren de diez ducados abajo y cristos de marfil y cipres y niños Jesús de cipres no pasando de una vara lo abemos de poder hacer cada uno de nos sin dar parte al otro y la que ecediere de esto a de ser partible entre nos por mitad como dicho es y los dichos tres retablos de Cazalla Aracena y Villamartin yo el dicho Juan Martinez Montañes e de recibir por cantidad conforme de la parte que queda a mi cargo e yo el dicho Joan de Oviedo acudir a el dicho Joan Martinez Montañes con la parte que la cumplire y e de ir cobrando y pagandole su parte de manera que de lo que fuere cobrando aya el rata por cantidad la parte que le perteneciere asi en las pagas que se fueren haciendo como en las ultimas que se hicieren despues de acabarlos.

- Iten nos obligamos de cumplir y haber por firme todo lo susodicho e no lo reclamar ni contradecir ni nos apartar de nos por ninguna causa ni razon que si lo contrario hicieremos ni nos valga y si lo contrario hicieremos no nos valga y la parte inobediente pague a la que obra por firme doscientos ducados de oro de pena (...fórmulas...) fecha la carta en Sevilla en el oficio de mi el escribano susoescrito que doy fe que conozco a los otorgantes y en este registro firmaron de sus nombres a cinco dias del mes de junio de mil e quinientos y noventa y seis años testigos Juan de Castilla y Francisco Fernandez. (Firmas y rúbricas) Pedro Vasco de Miranda; Juan de Oviedo; Juan Martínez Montañés; Francisco Fernández; Joan de Castilla.”

Antonio Joaquín Santos Márquez Universidad de Sevilla 